\title{
The role of endoscopic retrograde cholangiopancreatography in choledochal cysts and/or abnormal pancreatobiliary junction in children
} \author{
Jiri Nevoral ${ }^{3}$ \\ ${ }^{1}$ Clinic of Internal Medicine, University Hospital Motol, Prague, Czech Republic \\ ${ }^{2}$ Clinic of Paediatric Surgery, University Hospital Motol, Prague, Czech Republic \\ ${ }^{2}$ Clinic of Paediatry, University Hospital Motol, Prague, Czech Republic
}

Jiri Drabek ${ }^{1}$, Radan Keil ${ }^{1}$, Jan Stovicek ${ }^{1}$, Jindra Lochmannova ${ }^{1}$, Stepan Hlava ${ }^{1}$, Jiri Snajdauf ${ }^{2}$, Michal Rygl ${ }^{2}$,

Gastroenterology Rev 2017; 12 (4): 303-309

DOI: https://doi.org/10.5114/pg.2017.72107

Key words: abnormal pancreatobiliary junction, choledochal cyst, endoscopic retrograde cholangiopancreatography.

Address for correspondence: Jan Stovicek, Clinic of Internal Medicine, University Hospital Motol, V Uvalu 84, 15006 Prague, Czech Republic, phone: +42 0224433076, fax: +42 0224433075, e-mail: jan.stovik@gmail.com

\begin{abstract}
Introduction: Biliary cysts with an abnormal pancreatobiliary junction are one of the most common pancreatobiliary malformations. The main symptom is cholestasis; endoscopic retrograde cholangiopancreatography (ERCP) plays a key role in diagnosis. Aim: Retrospective evaluation of ERCP performed to diagnose abnormalities of the pancreatobiliary junction.

Material and methods: We retrospectively evaluated ERCP performed to diagnose abnormalities of the pancreatobiliary junction, mainly choledochal cysts, in 112 children between 1990 and 2011.

Results: We performed 112 examinations of 50 children with abnormal pancreatobiliary junction and choledochal cysts (15 males and 35 females, average age: 5 years, range: 1 month - 15 years). Cysts were associated with a common channel in $37(74 \%)$ cases, were not associated with a common channel in $9(18 \%)$ cases, and in $3(6 \%)$ cases the common channel lacked cysts. We performed endoscopic papilla sphincterotomy on 33 (66\%) patients; endoscopic drainage was performed 62 times, including 17 patients without papilla sphincterotomy. In 15 (30\%) cases, we only performed sphincterotomy. Extraction of lithiasis was done in 2 (4\%) cases. Both ERCP and magnetic resonance cholangiopancreatography (MRCP) were performed on 13 patients. There was concordance of the choledochal cyst and of the type of cyst in both methods; however, common channels could not be observed by MRCP. There was 1 serious complication (perforation after sphincterotomy) and 11 (9\%) mild adverse events.

Conclusions: When performed at an expert centre, ECRP is a safe and reliable procedure for children with choledochal cysts and/or an abnormal pancreatobiliary junction. Endoscopic retrograde cholangiopancreatography remains a reasonable alternative because MRCP has a limited ability to diagnose the precise anomalies of the pancreatobiliary junction and has no therapeutic capabilities.
\end{abstract}

\section{Introduction}

Choledochal cysts with or without an abnormal pancreatobiliary junction are among the most common pancreatobiliary malformations. The incidence of choledochal cysts in the western population is $1: 100,000$ $1: 150,000$ live births [1]. The rate is remarkably higher in Asian populations, with approximately two-thirds of cases occurring in Japan [2, 3].

Cystic disease of the biliary tree was first described in 1723 [1], and the first classification system for choledochal cysts was proposed by Alonso-Lej et al. in 1959
[4]. Contemporary classification was created by Todani et al. in 1977 [5] (Figure 1).

The aetiology of the choledochal cyst remains unclear. The most accepted theory of cyst origin supposes the influence of an abnormal pancreatobiliary junction when the common channel of the pancreatic and bile duct exists [6] (Figure 2). This theory postulates that the exceptionally long common channel allows mixing of the pancreatic and biliary juices, resulting in the activation of pancreatic enzymes, inflammation, and deterioration of the biliary duct wall, leading to dilation [6]. Other theories of origin suggest aganglionosis of 

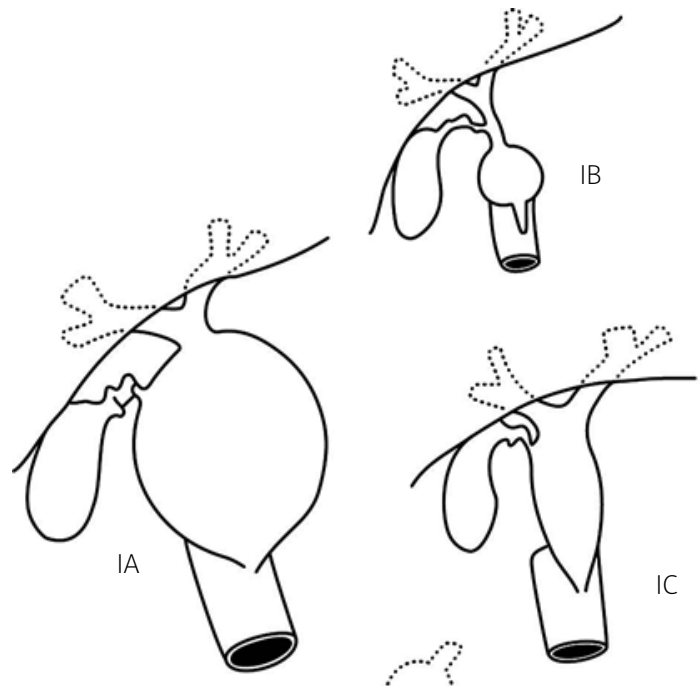

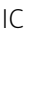
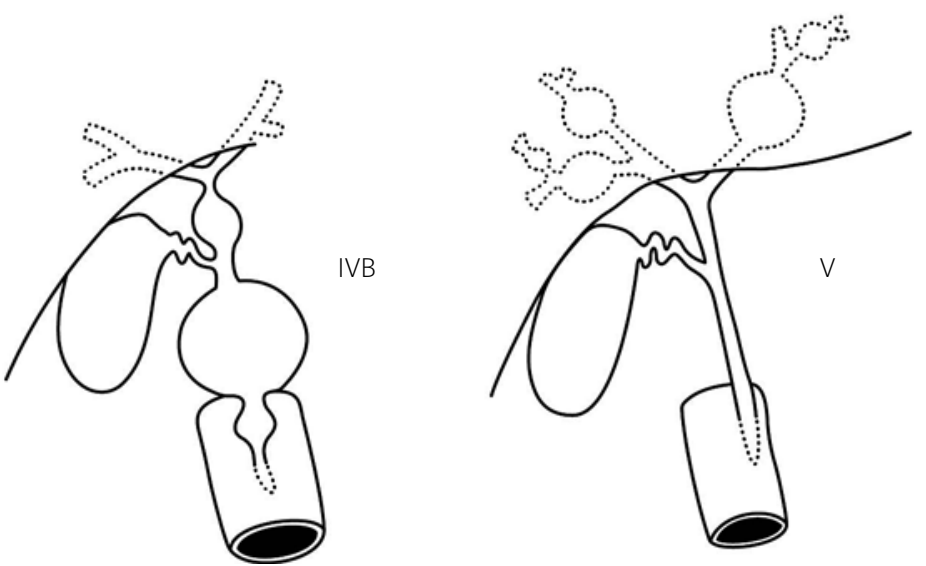

Figure 1. Todani's classification scheme for choledochal cysts [5]. Type IA - cystic dilation of the extrahepatic biliary tree. Type IB - focal, segmental dilation of the extrahepatic bile duct. Type IC - smooth fusiform dilation of the entire extrahepatic bile duct. Type II - discrete diverticuli of the extrahepatic duct. Type III - choledochocoele. Type IVA - combine intrahepatic and extrahepatic duct dilation. Type IVB - multiple extrahepatic bile duct dilations. Type $\mathrm{V}$ - Caroli disease. Adopted from [5]

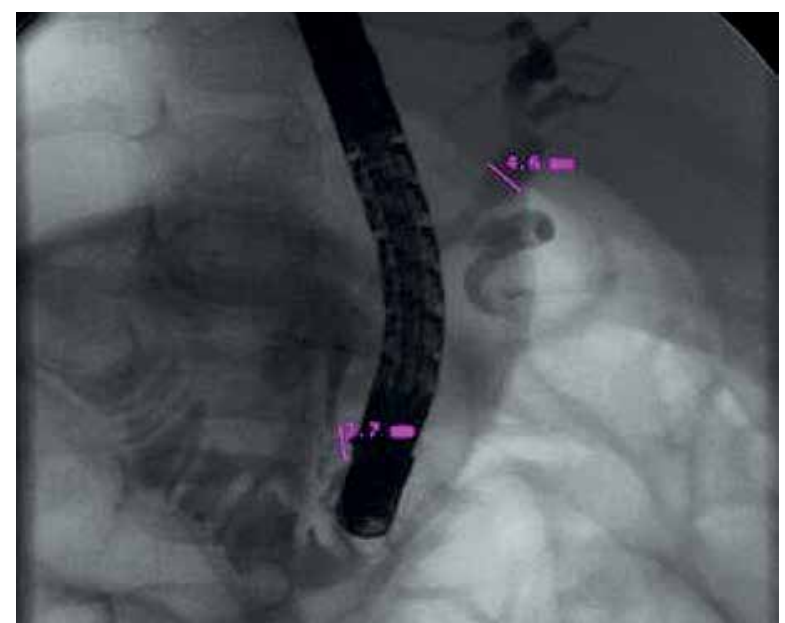

Figure 2. Endoscopic retrograde cholangiopancreatography: common channel the distal choledochus, foetal viral infection, or association with other inborn anomalies $[7,8]$. The origin of type- $V$ choledochal cysts probably differs from that of the other types of choledochal cysts, and is possibly due to dysfunctional remodelling of the ductal plate during embryogenesis [9, 10].

The relationship between choledochal cysts and carcinogenesis is important. The choledochal cyst is a premalignant state in which cancer occurs not only more often but also 10-15 years earlier than in the normal population [11]. The overall risk of cancer has been reported to be $10-15 \%$, and it increases with age [11].

Ultrasonography is the first imaging modality generally used for the biliary tree. This method shows a cystic mass in the right upper quadrant that is separate from the gallbladder, with the exception of type III and type $\vee$ cysts. Diagnosis of choledochal cysts requires 
a demonstration of the continuity of the cyst with the biliary tree, allowing them to be differentiated from other intra-abdominal cysts such as pancreatic pseudocysts, echinococcal cysts, or biliary cystadenomas [9]. Computed tomography is useful for demonstrating continuity of the cyst with the biliary tree, its relation to surrounding structures, and the presence of associated malignancy [12]. Computed tomographic cholangiography has been used to delineate the full anatomy of the biliary tree in order to correctly plan surgery, but unfortunately it has been reported to be less sensitive for imaging the pancreatic duct, which depends on the reflux of contrast into the ducts [12]. Of course, the drawback of computed tomography is the risk of nephro- and hepatotoxicity with the use of contrast as well as exposure to ionising radiation. Magnetic resonance imaging (MRI) is recommended for the diagnosis of choledochal cysts [13]. Magnetic resonance imaging and magnetic resonance cholangiopancreatography (MRCP) create images by differential signal intensity of stagnant pancreatic and bile secretion, with surrounding structures. Unfortunately, intraductal air, debris, stones, or protein plugs, all of which are common in patients with choledochal cysts, can interfere with the signal and alter visualisation [14].

For diagnosis and for delineating biliary anatomy, endoscopic retrograde cholangiopancreatography (ERCP) is very useful $[15,16]$. Endoscopic retrograde cholangiopancreatography provides information necessary for exact diagnosis and can play a very important therapeutic role as well. It enables several therapeutic modalities, such as papilla sphincterotomy and/or drainage or extraction of the cholelithiasis. In many cases, ERCP allows the postponing of operations until the patient is older. It is also useful for identifying an abnormal pancreatobiliary junction or ductal filling defects, which might be stones or cancers [17].

\section{Aim}

The aim of our study was the retrospective evaluation of ERCP performed at our centre for pancreatobiliary malformations. We assumed that ERCP is mostly useful for patients with obstructive jaundice and/or cholangitis, where decompression of the bile duct was performed. We also investigated whether ERCP enables precise diagnosis of the common channel.

\section{Material and methods}

We retrospectively analysed the ERCP examinations performed on children with an abnormal pancreatobiliary junction and/or choledochal cysts in our endoscopic unit from 1990 to 2011. On average, we perform 1600 ERCPs per year, approximately $3 \%$ of which are done on paediatric patients. During this period, we performed a total of 651 ERCPs on children. We carried out 112 examinations on 50 children with an abnormal pancreatobiliary junction and/or choledochal cyst. These patients were operated on at the paediatric surgery department of our hospital. This evaluation also includes seven other patients with choledochal cysts, who did not undergo ERCP before operation. Six of these patients only underwent MRCP (without administration of IV secretin), and one was diagnosed solely by ultrasound. These patients were directly operated on and ERCP was not indicated.

Our cohort consisted of 15 males and 35 females, with an average age of 5 years (range: 2 months 14 years). Patients were referred to our hospital from primary and secondary paediatric centres across the Czech Republic (approximately 10 million inhabitants).

Before ERCP was performed, an extensive diagnostic work-up including infectious, metabolite, or endocrine disorders and ultrasound examination was carried out in all patients. Magnetic resonance cholangiopancreatography was only performed for 19 asymptomatic patients, 13 of whom were consequently indicated for ERCP. The remaining 6 patients were directly operated on.

Informed consent was obtained from the patients' parents before ERCP. All examinations were performed by one of four endoscopists experienced in ERCP. All examinations were carried out on a fluoroscopic table under general anaesthesia with continuous monitoring of vital functions. We used a normal standard diagnostic lateroscope (Olympus J140) or a special paediatric lateroscope (Olympus PJF/PJF 7.5 duodenoscope). This 7.5-mm side-viewing endoscope has a 2-mm instrumentation channel with a cannula elevator. With the patient in the left lateral position, the endoscope was inserted into the second portion of the duodenum and positioned in front of the papilla. The patient was then moved to the prone position. Serum amylase levels, liver enzyme levels, and blood count were assessed in all patients at $6 \mathrm{~h}$ and $18 \mathrm{~h}$ after investigation.

The retrospective analysis was approved by the Local Ethics Committee.

\section{Results}

Between 1990 and 2011, our centre carried out 112 examinations of 50 children with abnormal pancreatobiliary junction and/or choledochal cyst. The most common symptoms that led to ERCP were abdominal pain (31 children, 62\%), icterus (27 children, 54\%), pancreatitis (12 children, $24 \%$ ), vomiting (8 children, 16\%), cholangitis (4 children, $8 \%$ ), growth retardation (3 children, $6 \%$ ), and elevated liver enzymes (2 children, $4 \%$ ). In $4(8 \%)$ children, the suspicion for cyst was raised prenatally (Table I). 
Table I. Symptoms of choledochal c ysts

\begin{tabular}{lcc} 
Symptom & N & Percentage \\
\hline Abdominal pain & 31 & 62 \\
\hline Icterus & 27 & 54 \\
\hline Pancreatitis & 12 & 24 \\
\hline Vomiting & 8 & 16 \\
\hline Cholangitis & 4 & 8 \\
\hline Growth retardation & 3 & 6 \\
\hline Liver enzyme elevation & 2 & 4 \\
\hline Prenatal suspicion & 4 & 8
\end{tabular}

We detected choledochal cysts in 46 (92\%) patients: type IA in $11(22 \%)$ patients, type IB in 1 (1\%) patient, type IC in $28(56 \%)$ patients, type II in $1(2 \%)$ patient, type III in $1(2 \%)$ patient, type IVA in $1(2 \%)$ patient, type IVB in $1(2 \%)$ patient, and type $\mathrm{V}$ in $2(4 \%)$ patients. A common channel was associated with cysts in 37 (74\%) patients, choledochal cysts without a common channel were observed in $9(18 \%)$ patients, and the common channel lacked cysts in $3(6 \%)$ patients. One (2\%) patient displayed a small pancreatic duct with the ostium linked directly to the common bile duct. We found stenosis in 32 (64\%) patients, sludge and mucus in 15 (30\%) patients, and lithiasis in 2 (4\%) patients (Table II, Figures 3-6).

We performed endoscopic papilla sphincterotomy in 33 (66\%) patients, endoscopic drainage 62 times, and drainage without sphincterotomy 17 times. Sphincterotomy alone was performed in 15 (30\%) patients, and we extracted stones from 2 (4\%) patients. The average elapsed time from ERCP (with insertion of stent) to the time of the operation was 7.1 months, ranging from 2 to 60 months.
Table II. Pathological findings

\begin{tabular}{|c|c|c|}
\hline Findings & $N$ & $\begin{array}{l}\text { Percentage } \\
\text { of all children }\end{array}$ \\
\hline Choledochal cysts: & 46 & 92.00 \\
\hline IA & 11 & 22 \\
\hline $\mathrm{IB}$ & 1 & 2 \\
\hline IC & 28 & 56 \\
\hline ॥ & 1 & 2 \\
\hline III & 1 & 2 \\
\hline IVA & 1 & 2 \\
\hline IVB & 1 & 2 \\
\hline V & 2 & 4 \\
\hline Common channel with cysts & 37 & 74 \\
\hline $\begin{array}{l}\text { Choledochal cyst w/o common } \\
\text { channel }\end{array}$ & 9 & 18 \\
\hline Common channel w/o cysts & 3 & 6 \\
\hline $\begin{array}{l}\text { Pancreatic duct directly to common } \\
\text { bile duct }\end{array}$ & 1 & 2 \\
\hline Stenosis & 32 & 64 \\
\hline Sludge and mucus & 15 & 30 \\
\hline Lithiasis & 2 & 4 \\
\hline Number of examinations & 112 & \\
\hline Number of children & 50 & \\
\hline
\end{tabular}

One serious complication occurred: periampular perforation after papilla sphincterotomy in a patient with a biliary cyst. This problem was treated surgically. There were also 8 (7\%) mild cases of hyperamylasaemia without clinical signs and 2 (2\%) cases of bleeding. Endoscopic treatment was sufficient in these cases.

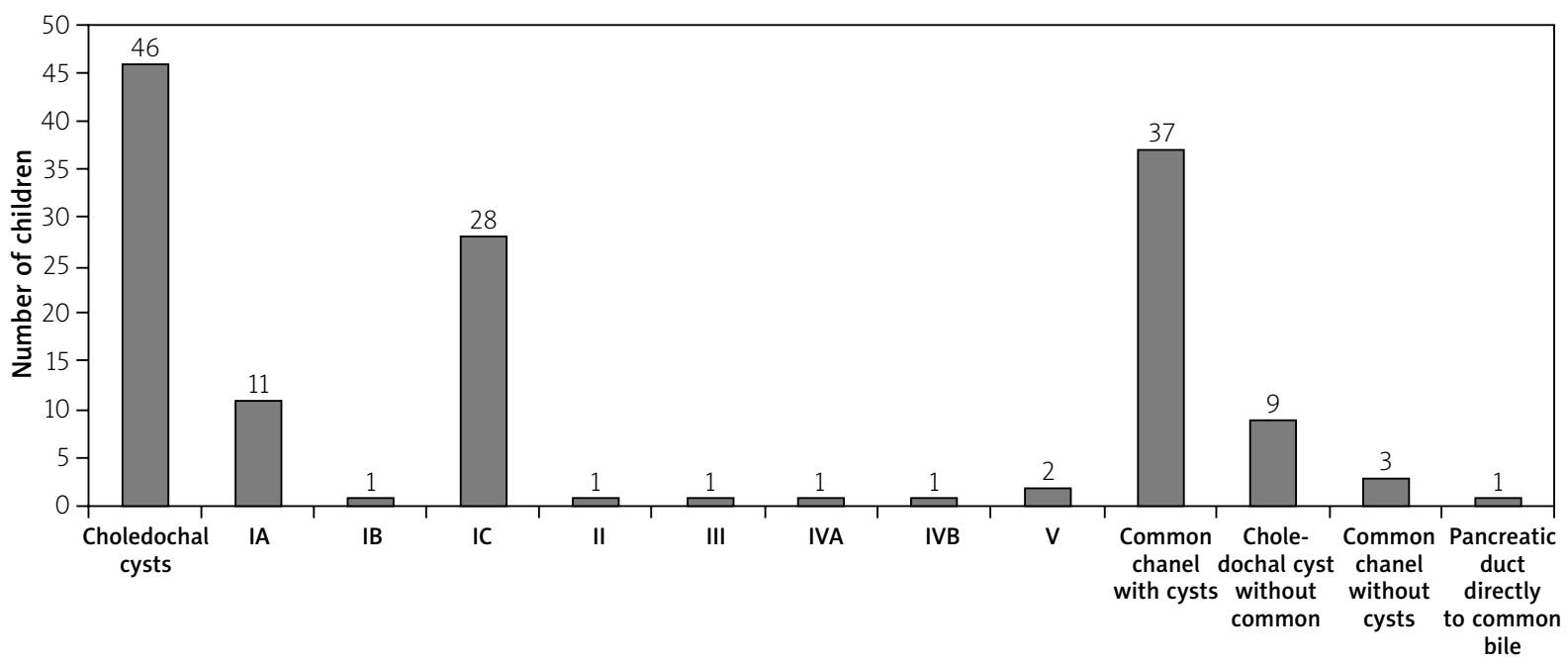

Figure 3. Pathological findings 


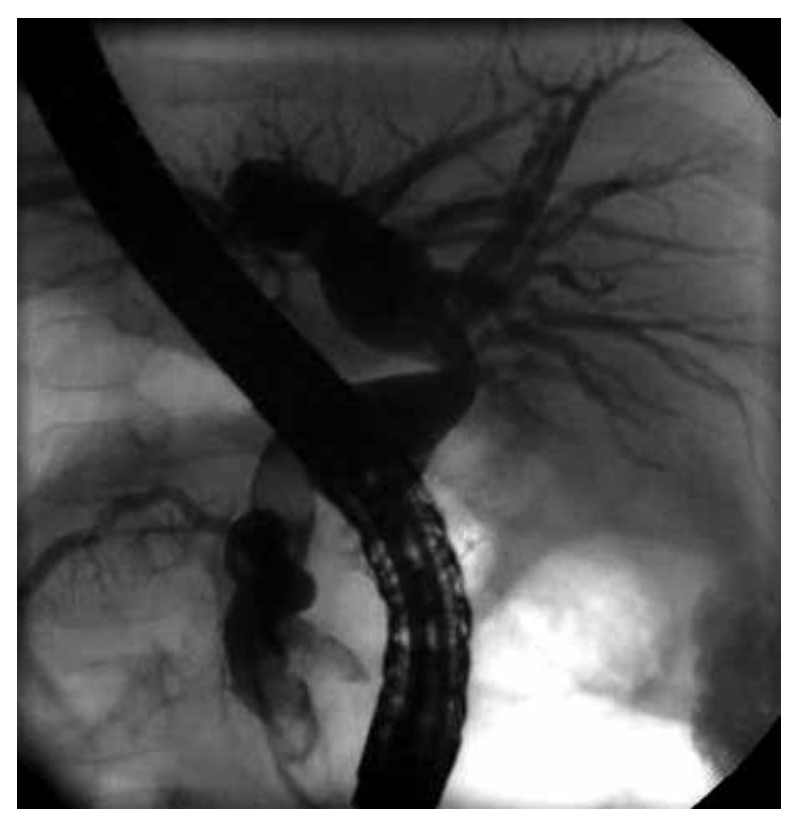

Figure 4. Biliary cyst, type IB

In 1 (1\%) child, we noted a retroperitoneal cumulation of contrast fluid. Endoscopic retrograde cholangiopancreatography failed in 2 (4\%) children. In 1 (1\%) case, only the Wirsung duct was filled, and diagnosis was based on MRCP. In 1 (0.9\%) case, we were unsuccessful in inserting a drainage tube.

Magnetic resonance cholangiopancreatography was also carried out in 13 children with a common channel and choledochal cysts. There was diagnostic concordance between ERCP and MRCP regarding diagnosis of the choledochal cyst and cyst type, but the common channel was not observed with MRCP.

\section{Discussion}

Successful diagnosis of choledochal cysts depends on close cooperation among gastroenterologists, radiologists, and surgeons. Diagnostic workup should not cease until there is enough information to plan the operation. It is usually necessary to combine ultrasonography, computed tomography, MRCP, and ERCP.

Some pancreatobiliary malformations can be diagnosed by ultrasound alone, which is a less invasive diagnostic method. Nevertheless, in most cases sonography is not sensitive and specific enough to distinguish between extrahepatic and intrahepatic cholestasis. Therefore, ultrasound can only provide a preliminary diagnosis. Differentiating a choledochal cyst from a hepatic cyst, hepatic abscess, acute fluid collection, or pancreatic pseudocyst may be difficult [18].

The use of MRI and MRCP is increasing for the noninvasive diagnosis of biliary and pancreatic diseases. Magnetic resonance cholangiopancreatography appears

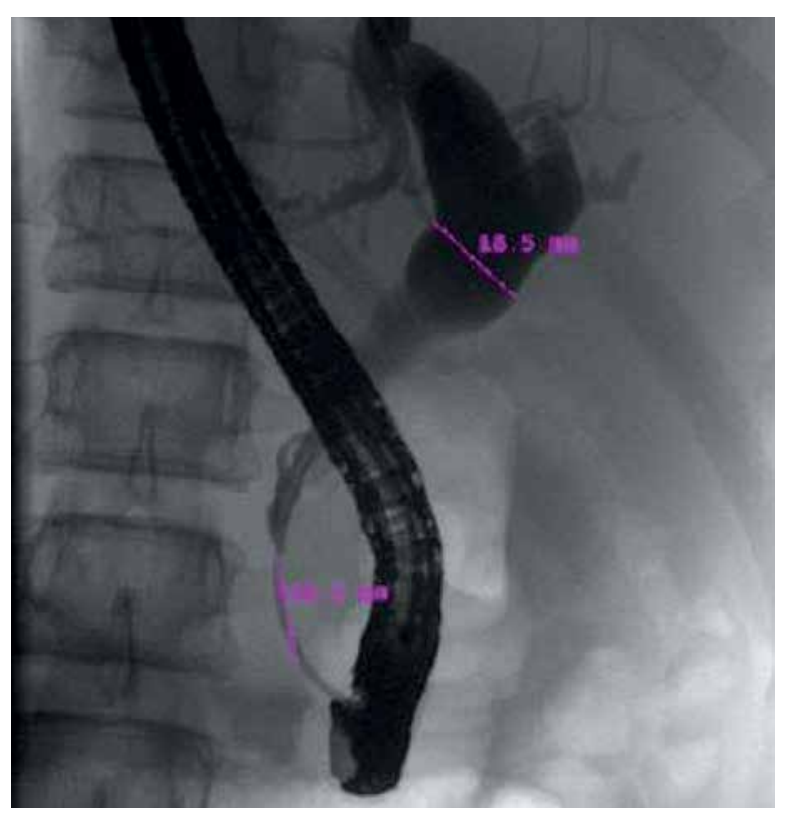

Figure 5. Biliary cyst, type IC

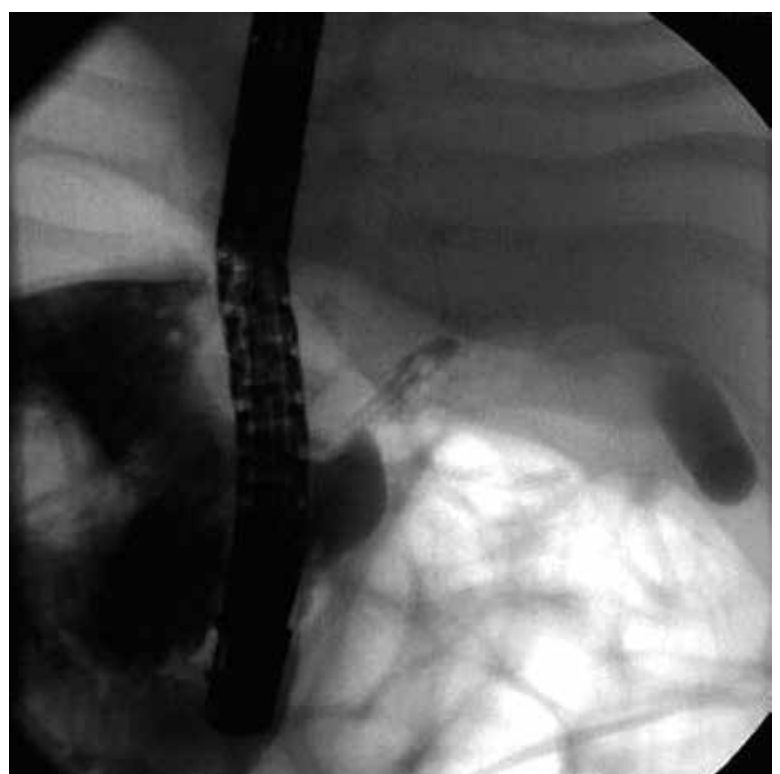

Figure 6. Endoscopic retrograde cholangiopancreatography of a biliary cyst, type IC, in a 2-month-old boy

to be reliable for the diagnosis of choledochal cysts, with a diagnostic accuracy of $82-100 \%$, but false-negative findings of the absence of abnormalities of the pancreatobiliary junction and the common pancreatobiliary channel are possible. In addition, small neoplasms of the gallbladder and bile duct may be missed [18]. Magnetic resonance cholangiopancreatography may aid the diagnosis of abnormal pancreatobiliary junction and/or choledochal cyst $[19,20]$, with the advantages 
Table III. Complications of ERCP

\begin{tabular}{lcc} 
Complication & N & Percentage \\
\hline Periampular perforation & 1 & 0.89 \\
\hline Hyperamylasaemia & 8 & 7.14 \\
\hline Bleeding & 2 & 1.79 \\
\hline $\begin{array}{l}\text { Retroperitoneal depot of contrast } \\
\text { fluid }\end{array}$ & 1 & 2.00
\end{tabular}

of safety and low invasiveness. However, more detailed assessment and critical evaluation are needed. Magnetic resonance cholangiopancreatography may supersede ERCP for the diagnosis of choledochal cysts, but MRCP seems to exhibit a limited ability to detect minor ductal anomalies or small choledochocoele [21]. In agreement with that previous study, in the present investigation we noted concordance in the diagnosis of choledochal cysts in 13 patients who underwent both ERCP and MRCP. Nevertheless, the common channel was not diagnosed by MRCP, but it was visualised by ERCP in all these patients.

According to the present study, ERCP can detect an abnormal pancreatobiliary junction and/or choledochal cysts in children; however, it is still often considered to be an invasive diagnostic procedure with a substantial risk of complications. Thus, ERCP should only be performed in cases where the appropriate diagnosis cannot be made by other less-invasive examinations, or when therapeutic performance is required $[22,23]$. Patients with choledochal cysts and/or an abnormal pancreatobiliary junctions account for approximately 10 percent of children examined by ERCP for icterus or cholestasis [16]. Often ERCP is necessary to solve obstructive jaundice and/or cholangitis in patients with choledochal cysts, which can be done minimally invasively via ERCP with papilla sphincterotomy and/or endoscopic drainage [24]. Sometimes it is advisable to postpone operation until the patient is older or healthier, a delay that is made possible by ERCP with endoscopic therapy. More than half of our cohort (54\%) had icterus, and $8 \%$ of our patients exhibited severe cholangitis, but ERCP with drainage allowed us to postpone operation on members of our cohort for an average of 7.1 months (range: 0.2-60 months). All patients with obstructive jaundice and/or cholangitis should be treated as soon as possible; ERCP allows the immediate performance of therapeutic procedures, even before operation.

Endoscopic papillosphincterotomy and/or stent insertion can prevent attacks of biliary pancreatitis, which are probably caused by the reflux of bile into the pancreatic duct. In our cohort, $24 \%$ of children had one or more attack/s of biliary pancreatitis before choledochal cysts were diagnosed.
In our experience, ERCP in children is overall a safe procedure, with drainage and with or without papilla sphincterotomy. We observed only one severe complication, which had to be treated by operation (Table III). This low complication rate may be related to the performance of ERCP by endoscopists who are highly experienced in the procedure. Moreover, all examinations were performed under general anaesthesia.

The high occurrence of a common channel in our patients with choledochal cysts supports Babbitt's theory of cyst origin. On the other hand, the occurrence of cysts without a common channel supports other theories of cyst origin [6].

\section{Conclusions}

Endoscopic retrograde cholangiopancreatography is a reasonable alternative for the diagnosis of choledochal cysts and/or abnormalities of the pancreatobiliary junction because MRCP still has limited ability to diagnose anomalies such as the common channel, as observed in the present investigation. In addition, ERCP provides therapeutic endoscopic modalities.

\section{Acknowledgments}

The authors thank Prof. C. J .J. Mulder and J. Jassica for their useful advice in the development of this manuscript.

Supported by the project (Ministry of Health, Czech Republic) for conceptual development of research organisation 00064203 (University Hospital Motol, Prague, Czech Republic).

\section{Conflict of interest}

The authors declare no conflict of interest.

\section{References}

1. Singham J, Yoshida EM, Scudamore $\mathrm{CH}$. Choledochal cysts, classification and pathogenesis. J Can Chir 2009; 52: 434-8.

2. Yamaoka K, Tazawa J, Koizumi K, et al. Choledochocele with obstructive jaundice: a case report and a review of the Japanese literature. J Gastroenterol 1994; 29: 661-4.

3. ONeill JA Jr. Choledochal cysts. Curr Probl Surg 1992; 29: 361-410.

4. Alonso-Lej F, Rever WB, Pessango DJ. Congenital choledochal cyst with a report of 2, and analysis of 94 cases. Int Abstr Surg 1959; 108: 1-30.

5. Todani T, Watanabe $Y$, Narusue $M$, et al. Congenital bile duct cysts, classification, operative procedures and review of thirty-seven CASE including cancor arising from choledochal cyst. Am J Surg 1977; 134: 263-9.

6. Babbit DP. Congenital choledochal cysts: new ethiological concept based on anomalous relationships of the common bile duct and pancreatic bulb. Ann Radiol (Paris) 1969; 12: 231-40. 
7. Cheng SP, Yang TL, Jeng KS, et al. Choledochal cysts in adults: aetiological considerations to intrahepatic involvement. ANZ J Surg 2004; 74: 964-7.

8. Yotsuynagy S. Contribution to aetiology and pathology of idiopathic cystic dilatation of the common bile duct with report of three cases. Gann 1936; 30: 601-752.

9. Levy AD, Rohrman CA. Biliary cystic disease. Curr Probl Dian Radiol 2003; 32: 233-63.

10. Fulcher AS, Turner MA, Sanyal AJ. Case 38: Caroli's disease and renal tubular ectasia. Radiology 2001; 220: 720-2.

11. Tsuchiya R, Harada N, Ito T, et al. Malignant tumors in choledochal cysts. Ann Surg 1977; 186: 22-8.

12. Lam WM, Lam TP, Saing H. MR cholangiography and CT cholangiography of pediatric patients with choledochal cysts. AJR Am Roentgenol 1999; 173: 401-5.

13. Kim MJ, Han SJ, Yoon CS, et al. Cholangiopancreatography to reveal anomalous pancreatobiliary ductal union in infants and children with choledochal cysts. AJR Am J Roentgenol 2002; 179: 209-14.

14. Arhanskiy Y, Vyas PK. Type IV. Choledochal cyst presenting with obstructive jaundice: role of MR cholangiopancreatography in preoperative evaluation. AJR Am J Roentgenol 1998; 171: 457-8.

15. Pietrabissa A, Boggi U, Di Candio G, et al. Unsuspected choledochal cyst during laparostopic cholecystectomy. Surg Endosc 1995; 9: 1127-9.

16. Keil R, Šnajdauf J, Rygl $M$, et al. Diagnostic efficacy of ERCP in cholestatic infants and neonates - a retrospective study on large series. Endoscopy 2010; 42: 121-6.

17. Park KB, Auh YH, Kim JH, et al. Diagnostic pitfails in the cholangiopancreatographic diagnosis of choledochoceles: cholangiographic duality and its effect on visualisation. Abdom Imaging 2001; 26: 48-54.

18. Sawyer M. Imaging in choledochal cyst. Emedicine.medscape. com/article/366004-overview, Apr 12, 2011.

19. Norton KI, Glass RB, Kogan D, et al. MR cholangiography in the evaluation of neonatal cholestasis: initial results. Radiology 2002; 222: 687-91.

20. Chavhan GB, Babyn PS, Manson D, et al. Cholangiography: principles, technique and clinical applications. Radiographics 2008; 28: 1951-62.

21. Park DH, Kim M, Lee SK, et al. Can MRCP replace the diagnostic role of ERCP for patients with choledochal cysts ? Gastrointest Endosc 2005; 62: 360-6.

22. Schaefer JF, Kirschner HJ, Lichy $M$, et al. Highly resolved free-breathing magnetic resonance cholangiopancreatography in the diagnostic workup of pancreatobiliary diseases in infants and young children - initial experiences. J Pediatr Surg 2006; 41: 1645-51.

23. Guideline for the evaluation of cholestatic jaundice in infants: Recomendation of the North American Society for Pediatric Gastroenterology, Hematology and Nutrition. J Pediatr Gastroenterol Nutr 2004; 39: 115-28.

24. Keil R., Šnajdauf J, Štuj J, et al. Endoscopic retrograde cholangiopancreatography in cholestatic infants - our experience. Endoscopy 2003; 35 (Suppl II): A225.

Received: 21.04 .2015

Accepted: 28.03.2017 